\title{
Diabetes mellitus triggers oxidative stress in the liver of alloxan-treated rats: a mechanism for diabetic chronic liver disease ${ }^{1}$
}

\author{
Amanda Natália Lucchesi', Natália Tavares de Freitas ${ }^{I I}$, Lucas Langoni Cassettari ${ }^{\text {III, }}$ Sílvio Fernando Guideti Marques ${ }^{\mathrm{IV}}$, César \\ Tadeu Spadella ${ }^{\mathrm{V}}$ \\ IFellow PhD degree, Postgraduate Program in General Basis of Surgery, Faculty of Medicine, UNESP, Botucatu-SP, Brazil. Technical procedures, \\ acquisition of data, manuscript preparation. \\ IIGraduate student, Faculty of Medicine, UNESP, Botucatu-SP, Brazil. Technical procedures. \\ IIIFellow PhD degree, Postgraduate Program in General Basis of Surgery, Faculty of Medicine, UNESP, Botucatu-SP, Brazil. Acquisition, analysis and \\ interpretation of data. \\ ${ }^{\text {IV }} \mathrm{PhD}$, Assistant Professor, Methodist University of Piracicaba (UNIMEP), Sao Paulo, Brazil. Standardization of the method and biochemical dosages \\ of the oxidative stress biomarkers. \\ ${ }^{\mathrm{v}} \mathrm{PhD}$, Full Professor, Department of Surgery and Orthopedics, Faculty of Medicine, UNESP, Botucatu-SP, Brazil. Supervised all phases of the study, \\ manuscript writing, critical revision.
}

\begin{abstract}
PURPOSE: To investigate whether Diabetes mellitus chemically induced by alloxan is capable of changing, in the long term, the oxidative balance in the liver tissue of rats.

METHODS: Sixty male Wistar rats, weighing 250-280g, were randomly distributed into two experimental groups: NG - 30 nondiabetic control rats; DG - 30 alloxan- induced diabetic rats without any treatment for the disease. Each group was further divided into three subgroups containing ten rats each, which were sacrificed after one, three and six months of follow-up, respectively. Blood glucose, urinary glucose, glycosylated hemoglobin and insulin were determined in the plasma of all animals at the beginning of the experiment and prior to all sacrifice periods. The concentrations of lipid hydroperoxides (HP) and the activity of antioxidant enzymes superoxide dismutase (SOD), catalase (CAT) and glutathione peroxidase (GSH-Px) were also measured in the liver tissue of all animals. RESULTS: Rats from the DG group showed high levels of blood glucose, urinary glucose, and glycosylated hemoglobin, with significantly lower plasma insulin levels than those observed in NG rats $(p<0.001)$. Diabetic animals also showed increased concentration of HP free radicals in the liver tissue as compared to those shown by NG animals after one, three and six months of follow-up. In contrast, the antioxidant activity of the enzymes SOD, CAT and GSH-Px was significantly reduced in all follow-up periods ( $\mathrm{p}<0.01$ ).

CONCLUSIONS: Diabetes determines oxidative stress in the liver, which is characterized by increased concentration of reactive oxygen species (ROS) in tissue and significant reduction in their antioxidant defenses. Such oxidative unbalance in the liver cells may play a relevant role in the genesis of the diabetic chronic liver disease, including the non-alcoholic fatty liver disease and its occasional progression to steatohepatitis and cirrhosis.
\end{abstract}

Key words: Diabetes Mellitus. Liver Diseases. Oxidative Stress. Alloxan. Rats. 


\section{Introduction}

Accumulated literature reviews suggest that cellular oxidative stress plays a crucially important role in the genesis of hyperglycemia-related tissue damage. According to these reports, increased production of reactive oxygen species (ROS) in diabetes would be capable of initiating or promoting the development of chronic diabetic lesions on vessels, retina, kidneys, nerves and on the other organs whether antioxidant defenses of diabetic organism are unable to block the harmful action of such substances ${ }^{1-4}$.

Clinical and experimental findings suggest that the liver, similarly to other organs, may also be affected by diabetes mellitus $(\mathrm{DM})$ in the long-term ${ }^{5-11}$. Liver compromising by diabetes is known by the designation of non-alcoholic fatty liver disease (NAFLD), which, histologically, cannot be distinguished from ethanol-induced hepatic steatosis ${ }^{5}$. NAFLD is characterized by being a pathological clinical syndrome with a broad spectrum of histological manifestations that can take from a benign course to more severe forms of chronic liver disease, such as nonalcoholic steatohepatitis, hepatic cirrhosis and, occasionally, liver carcinoma ${ }^{9,12}$.

Recent clinical and experimental studies suggest that once NAFLD is established in diabetes, the already compromised liver could be affected by ROS, and hepatocellular damage aggravation could occur with inflammation and progression to steatohepatitis and cirrhosis ${ }^{10,13-18}$.

However, differently from other chronic diabetic lesions, DM has been neglected as a cause of chronic liver disease, considering the great importance given to other pathogenic agents. Until not long ago, a large number of patients with cirrhosis, the cause of which was considered to be "cryptogenic", today have, in diabetes, a very well-established cause ${ }^{19}$. Hence, this study aimed at evaluating how hepatic oxidative stress behaves in a DM animal model with the purpose to establish the actual potentialities of such cellular aggression mechanism in the genesis and development of diabetic chronic liver disease. We hope this knowledge can to base proposals for use of antioxidants agents capable of neutralizing the harmful effects of ROS on the liver.

\section{Methods}

Animals and diabetes induction

Use of laboratory animals followed the ethical code for animal experimentation of the Council for International Organization of Medical Sciences (CIOMS), and was approved by the Animal Experimentation Ethics Committee of UNESP.

Sixty male Wistar Rats, weighing $250 \mathrm{~g}$ to $280 \mathrm{~g}$, from the Animal Colony, Faculty of Medicine - UNESP, Botucatu-SP, Brazil were used in this experiment. The animals were randomly distributed into two experimental groups: Normal Group (NG), with 30 non-diabetic control rats, and the Diabetic Group (DG), with 30 diabetic rats without any treatment for the disease. Each experimental group was divided into three subgroups of ten animals each, which were sacrificed after one, three and six months of follow-up, respectively.

Diabetes was induced by the endovenous administration of 2\% alloxan (Sigma Chemical Company, USA), at a dose of $42 \mathrm{mg} / \mathrm{kg}$ of body weight by using one of the tail veins. Only animals with clinical signs of severe diabetes and fasting glycemia $>250 \mathrm{mg} / \mathrm{dL}$, in two successive determinations performed seven and 14 days after diabetes induction, were utilized in the experiment. Rats who died throughout the experiment were replaced to avoid compromising the initial size of the sample.

\section{Analyzed parameters}

Clinical (body weight, water intake, food intake and diuresis) and laboratory (blood glucose, urinary glucose, glycosylated hemoglobin and plasma insulin) parameters were obtained at the beginning of the experiment (14th day of followup or diabetes onset) and prior to each sacrifice period in all animals. Blood collection in the follow-up was performed by a sectioning the animal's tail under anesthesia and at sacrifice by heart puncture with an open thorax. Anesthesia was performed by using ketamine at a dose of $100 \mathrm{mg} / \mathrm{Kg}$ of body weight associated with xylazine at a dose of $50 \mathrm{mg} / \mathrm{Kg}$ of body weight (Rhobifarma Ind. Farmacêutica Ltda., Hortolândia - SP, Brazil), administered by the intramuscular route. Clinical data were obtained by using metabolic cages. Euthanasia was performed by hypovolemia and section of the infradiaphragmatic vena cava.

\section{Measurements of biochemical markers of oxidative stress}

Fresh fragments representative of liver tissue were collected from all animals at sacrifice, frozen in an ultrafreezer at $-80^{\circ} \mathrm{C}$ for dosage of lipid hydroperoxide (HP) concentration and the measurement of the activity of antioxidant enzymes superoxide dismutase (SOD), catalase (CAT) and glutathione peroxidase (GSH-Px).

The dosages of blood glucose were performed by the glucose oxidase method (Johnson \& Johnson, USA), glycosylated 
hemoglobin by agarose gel electrophoresis in total blood (Sebia, France), and plasma insulin by solid-phase radioimmunoassay (Diagnostic Products Corporation, USA). The biochemical markers of hepatic tissue oxidative stress were dosed by using specific reagents (Cayman Chemical Company, USA).

\section{Statistical analysis}

The analysis of clinical and laboratory variables and biochemical markers of oxidative stress was performed by Analysis of Variance complemented with Tukey's multiple comparisons test (variables with homogeneous distribution) and by Mann-Whitney and Kruskal-Wallis' non-parametric analysis (variables with heterogeneous distribution) at the level of significance of $5 \%$ or $\mathrm{p}<0.05$.

\section{Results}

\section{Clinical and laboratory findings}

Rats in DG showed evident clinical signs of severe diabetes, with weight loss, polyuria, polydpsia and polyphagia, associated with a state of hyperglycemia and persistent hyperglucohemoglobinemia and hypoinsulinemia when compared with rats in NG $(p<0.001)$. Rats in DG also remained diabetic during the whole follow-up period when compared to their respective controls. Figures 1 and 2 illustrate the clinical and laboratory findings obtained in animals from the two experimental groups in the respective sacrifice periods.

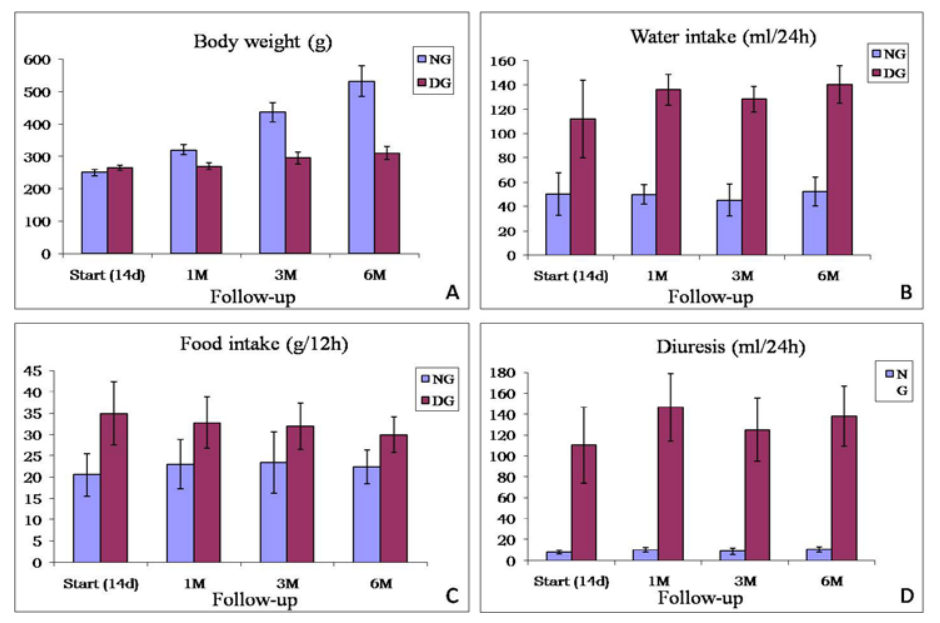

FIGURE 1 - Means \pm SD of body weight (A), water intake (B), food intake (C) and diuresis (D) in animals from the two experimental groups during follow-up.
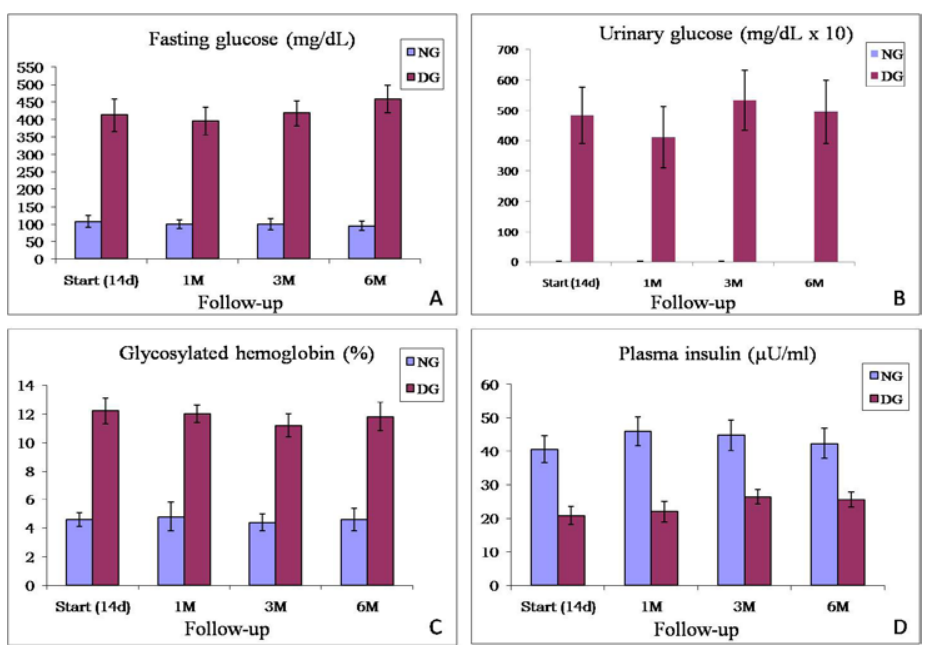

FIGURE 2 - Means \pm SD of fasting glycemia (A), urinary glucose (B), glycosylated hemoglobin (C) and plasma insulin (D) in animals from the two experimental groups during follow-up.

\section{Biochemical markers of oxidative stress}

The concentration of lipid hydroperoxides (HP) in the hepatic tissue was significantly high $(\mathrm{p}<0.01)$ in animals from $\mathrm{DG}$, at the dosages made with one, three and six months of followup as compared with those observed in rats from NG. Contrarily, the antioxidant activity of the liver tissue associated with enzymes superoxide dismutase (SOD), catalase (CAT) and glutathione peroxidase (GSH-Px) were significantly reduced in these periods $(\mathrm{p}<0.01)$.

Oxidative stress in the liver tissue also showed a positive relationship with the duration of the hyperglycemic state, and it was more intense in the animals later sacrificed, regardless of the variation in glycemic values. Table 1 illustrates the results found in animals from the two experimental groups in the respective sacrifice periods. 
TABLE 1 - Means \pm SD for the concentration of lipid hydroperoxides (HP) and for the activity of antioxidant enzymes superoxide dismutase (SOD), catalase (CAT) and glutathione peroxidase (GSH-Px) in the two experimental groups at the respective sacrifice moments.

\begin{tabular}{ccccc}
\hline \multicolumn{5}{c}{ Follow-up } \\
\hline Parameters & Groups & 1M & 3M & 6M \\
\hline \hline $\begin{array}{c}\text { HP } \\
(\mathrm{nmol} / \mathrm{g})\end{array}$ & NG & $42.92 \pm 0.65$ & $45.23 \pm 0.53$ & $52.14 \pm 0.93$ \\
& DG & $115.82 \pm 0.74^{*}$ & $128.36 \pm 1.18^{*}$ & $147.63 \pm 2.43^{*}$ \\
SOD & NG & $10.72 \pm 0.33$ & $10.36 \pm 0.47$ & $9.51 \pm 0.28$ \\
$(\mathrm{U} / \mathrm{g})$ & DG & $6.79 \pm 0.25^{*}$ & $5.54 \pm 0.24^{*}$ & $5.48 \pm 0.42^{*}$ \\
& & & & \\
$\mathrm{CAT}$ & $\mathrm{NG}$ & $77.47 \pm 1.05$ & $72.73 \pm 0.60$ & $69.27 \pm 0.69$ \\
$(\mu \mathrm{mol} / \mathrm{g})$ & $\mathrm{DG}$ & $47.79 \pm 0.99^{*}$ & $61.25 \pm 0.43^{*}$ & $56.41 \pm 0.84^{*}$ \\
& & & & \\
$\begin{array}{c}\mathrm{GSH}-\mathrm{Px} \\
(\mu \mathrm{mol} / \mathrm{min} / \mathrm{g})\end{array}$ & $\mathrm{NG}$ & $10.61 \pm 0.29$ & $9.87 \pm 0.44$ & $9.07 \pm 0.20$ \\
\hline
\end{tabular}

HP: $* \mathrm{NG}<\mathrm{DG}$ for $\mathrm{p}<0.01$ at 1,3 and 6 months; $\mathrm{SOD} / \mathrm{CAT} / \mathrm{GSH}-\mathrm{Px}: \mathrm{NG}>\mathrm{DG}$ for $\mathrm{p}<0.01$ at 1,3 and 6 months.

\section{Discussion}

Although oxidative stress plays a relevant role in the genesis and development of chronic diabetic complications, the intrinsic mechanisms of this cellular aggression pathway are not fully known.

In our study, it was shown that the liver tissue of diabetic rats without any treatment for the disease showed remarkably increased production of lipid hydroperoxide oxidant radicals (HP) associated with persistent reduction in the activity of antioxidant enzymes SOD, CAT and GSH-Px in all periods of evaluation in the experiment. It was also observed that the level of oxidative stress in the liver showed a close relationship with the duration of the diabetic state, thus indicating that the intensity of alterations in the oxidant balance is, in fact, more related to the duration of the disease than to the magnitude of glycemic values.

However, if oxidative damage induces or promotes lesions in the liver and other organs of diabetic patients or if it is simply a phase comprising a complex flow of phenomena culminating in chronic diabetic lesions are controversial facts ${ }^{4}$.

It is widely known, however, that oxidative stress plays an important role in the mechanisms of regulation of cellular adherence, proliferation, migration and signaling of the extracellular matrix ${ }^{20}$, thus, being able to change the structure and permeability of the cell membranes and intracellular organelles, such as mitochondria, the rough endoplasmic reticulum, and affecting ion exchange, the oxidative process and protein synthesis $^{21}$. Reactive oxygen species (ROS) generation may also attack lysosomes and cellular DNA, making cells more susceptible to the damage caused by toxic products and mutations that may lead to cellular death ${ }^{21,22}$.

On the other hand, oxidative stress does not seem to be the only mechanism implicated in the genesis of chronic diabetic complications, as shown by several studies ${ }^{4,20,23-25}$. A well-known mechanism of cellular damage is mediated by the advanced products of non-enzymatic glycolysation (AGE). These substances result from spontaneous reactions of free sugars with several proteins, and they are capable of initiating a large variety of abnormal cellular responses, such as the inappropriate expression of growth factors and proinflammatory cytokines, accumulation of the extracellular matrix and vasoregulatory dysfunction ${ }^{23,24}$.

Another mechanism of cellular aggression is the activation of the polyol pathway. According to Khan et al. $^{4}$, the body tissues that do not depend on insulin to capture glucose, such as the nervous system, can, as a result of the high levels of circulating glucose, also lead to glucose increase intracellularly. Such intracellular hyperglycemia, in turn, can activate adenosine dinucleotide phosphate oxidation (NADPH + ), which acts on the conversion of glucose into sorbitol. Sorbitol accumulation in the intracellular environment increases cell osmolarity and can cause cell damage and death. The activation of the polyol pathway in diabetic individuals can also indirectly decrease the formation of antioxidant enzyme glutathione peroxidase (GSH-Px), since such process depends on normal levels of reduced NADPH, which may have been consumed in the change of glucose into sorbitol. As a result, the antioxidant activity exerted by GSH-Px may be reduced in diabetic patients, secondarily to the activation of the polyol pathway, and this may partly explain the low levels in the activity of that enzyme in the liver tissue of our diabetic animals.

Increased intracellular glucose in insulin-independent tissues can also activate the hexosamine pathway. In this pathway, glucose is changed into acetylglucosamine-derived (UDP-N-acetylglucosamine) compounds, which are responsible for modulating the expression of proteins that regulate the production of the plasminogen-I-inhibiting factor (PAI-I) and of the transforming growth factor beta 2 (TGF- $\beta 2$ ). This may foster the formation of thrombi in vessels and excessive collagen matrix production in the vascular endothelium. These mechanisms are directly implicated in the genesis and development of diabetic microangiopathy ${ }^{20}$.

Chronic hyperglycemia can also activate the protein 
kinase C (PKC) pathway, another mechanism responsible for microvascular alterations in diabetes. Such protein can be activated in response to increased production of diacylglycerol, a compound formed from the oxidation of free fatty acids when the organism is unable to obtain energy from intracellular glucose. PKC activation, however, reduces the concentrations of nitric oxide (NO), a vasodilator compound, thus increasing the concentrations of the TGF- $\beta 2$ and of the vascular endothelial growth factor (VEGF), which are responsible for vascular vasoconstriction, blood flow reduction and narrowing of the vascular lumen in the diabetic patient's capillary bed of the retina, kidneys, nerves and peripheral $\operatorname{arteries}^{25}$.

According to Méndez-Sánchez et al. ${ }^{19}$, the persistence of a diabetic state and of chronic stress in liver cells seems to be one of the most important predictive factors for cirrhosis development in diabetic and obese patients with non-alcoholic fatty degeneration of the liver (NAFLD). Several physiopathological mechanisms have been proposed to explain hepatocellular damage in these patients, whose common factors are increased liver capacity to oxidize substrates and insulin resistance.

Increased oxidation of free fatty acids (FFA) by the liver can generate ROS, which can lead to lipid peroxidation processes, structural and functional alterations in cells and cell death ${ }^{26}$. In physiological conditions, the organism's antioxidant defenses can neutralize the harmful effects of such substances. In pathological conditions, however, such as in diabetes, the metabolic balance is broken, and oxidative stress is initiated. The maintenance of oxidative stress to the hepatic level triggers adaptation responses to chronic stress by the liver, including the activation and/or inhibition of various molecular sites responsible for the transduction and transcription of signs that control the biological cell cycle ${ }^{27}$. Alterations in the biological cell cycle, in turn, eventually compromise the liver's replication and regeneration capacity, leading to apoptosis or cell death. On the other hand, FFA excess in the liver may isolatedly lead to the apoptosis of hepatocytes, thus being considered one of the cellular damage mechanisms commonly described in patients with NAFLD ${ }^{28}$.

Various studies on the physiopathology of NAFLD have shown that the liver of obese men and animals is more sensitive to the harmful stimuli of chronic oxidative stress, particularly in response to the aggression of proinflammatory cytokines, such as the tumor necrosis factor alpha (TNF- $\alpha$ ), and to bacterial endotoxins ${ }^{28-30}$. Evidence in the literature, however, suggests that chronic oxidative stress of the liver not only is capable of initiating molecular alterations that lead to fat accumulation in the organ, but also of promoting alterations that result in steatohepatitis and in cirrhosis. Sanyal et al. ${ }^{31}$ reported that insulin resistance also plays an important role in NAFLD development to steatohepatitis, considering the fact that it negatively influences intracellular routes in the hepatocyte. Such hypothesis is shared by other authors ${ }^{32,33}$ who have described the association between insulin resistance and hypertrophy of the liver's microsomal oxidative function due to increased activity in the intramitochondrial cytochrome P-450 system, which is related to the loss of the insulin inhibitory effect in the mechanisms of cellular oxidative stress regulation.

It is certain, however, that in the development of NAFLD to steatohepatitis, and from the latter to cirrhosis, factors that act within and out of the liver are involved. An example of such fact is the increased resistance to insulin action to the peripheral level, which increases the oxidation of fatty acids in the adipose tissue and enhances the provision of FFA to the liver, thus predisposing to ROS generation ${ }^{11,31}$. An experimental study conducted by Jensen et $a l .{ }^{34}$ suggested that the relationship between obesity, insulin resistance and steatohepatitis has the increased release of FFA from the adipose tissue, particularly that located in the viscera, as a common factor. Increased visceral obesity fosters FFA release directly into the portal venous system and from there immediately to the liver.

In the liver, FFAs stimulate neoglucogenesis and triglyceride synthesis, compromising the ability of insulin to suppress the release of hepatic glucose, which aggravates hyperglycemia. On the other hand, the accumulation of lipids in the liver, and their later oxidation, are also under influence of the amount of leptin secreted and the level of tissue sensitivity to that substance. Leptin is a protein codified by a gene (ob) found in obese individuals; it is predominantly expressed in adipocytes and is capable of regulating body weight, metabolism and reproductive function $^{35}$. To Portincasa et $a l .{ }^{11}$, the beginning of NAFLD progression to steatohepatitis and cirrhosis involves two crucial points: the first is related to patients' risk factors, such as genetic defects, insulin resistance, hyperinsulinemia, obesity and lifestyle; the second is related to the alterations in intra- and extramolecular mechanisms that lead to hepatic damage, including FFA oxidation, the formation of ROS, lipid peroxidation and the release of proinflammatory cytokines responsible for inflammation, necrosis and hepatocellular fibrosis. According to Dowman et $a l .^{36}$, the accumulation of triglycerides in the liver, or steatosis, increases that organ's susceptibility to damage mediated by inflammatory cytokines/adipocytokines or by hepatocellular oxidative stress, thus fostering NAFLD progression to steatohepatitis and/or fibrosis. According to those researchers, FFAs are also capable of acting directly on the liver, promoting hepatic damage. These compounds 
can be both submitted to $\beta$-oxidation and sterified with glycerol in order to form triglycerides, which leads to fat accumulation in the liver. Within that organ, FFAs can also increase hepatic oxidative stress and/or activate inflammatory pathways that contribute to NAFLD progression.

Roskams et $a l .{ }^{37}$ postulated that, in healthy individuals, dead liver cells stimulate the replication of mature hepatocytes so as to reconstitute the damaged hepatic tissue. However, in the presence of NAFLD, hepatic oxidative stress can inhibit the replication of mature hepatocytes, resulting in the expansion of hepatic progenitor cells (oval cells) which can differentiate into hepatocyte-like cells, but are not hepatocytes. The increase in the number of oval cells and of hepatocyte-like cells, in turn, is strongly correlated with NAFLD development to hepatic fibrosis as well as to hepatocellular carcinogenesis.

\section{Conclusions}

Diabetes determines oxidative stress in the liver, which is characterized by increased concentration of reactive oxygen species (ROS) in tissue and significant reduction in their antioxidant defenses. Such oxidative unbalance in the liver cells may play a relevant role in the genesis of the diabetic chronic liver disease, including the non-alcoholic fatty liver disease and its occasional progression to steatohepatitis and cirrhosis.

\section{References}

1. Bloch-Dam IA, Bashan N. Proposed mechanisms for the induction of insulin resistance by oxidative stress. Antioxid Redox Signal. 2005; 7:1553-67.

2. Davi G, Falco A, Patrono C. Lipid peroxidation in diabetes mellitus. Antioxid Redox Signal. 2005;7:256-68.

3. Kaneto H, Nakatani Y, Kawamori D, Miyatsuka T, Matsuoka TA, Matsuhisa M, Yamasaki Y. Role of oxidative stress, endoplasmic reticulum stress, and c-Jun N-terminal kinase in pancreatic betacell dysfunction and insulin resistance. Int J Biochem. Cell Biol. 2006;38:782-93.

4. Khan ZA, Farhangkhoee H, Chakrabarti S. Towards newer molecular targets for chronic diabetic complications. Curr Vasc Pharmacol. 2006;4:45-57.

5. Harrison S.A, Diehl AM. Fat and the liver - a molecular overview. Semin Gastrointest Dis. 2002;13:3-16.

6. Li Z, Clark J, Diehl AM. The liver in obesity and type 2 diabetes mellitus. Clin Liver Dis. 2002;6:867-77.

7. Adams LA, Angulo P. Recent concepts in non-alcoholic fatty liver disease. Diabet Med. 2005;22:1129-33.

8. Leclercq IA, Da Silva Morais A, Schroyen B, Van Hul N, Geerts A. Insulin resistance in hepatocytes and sinusoidal liver cells: mechanisms and consequences. J Hepatol. 2007;47:142-56.

9. Yeh MM, Brunt EM. Pathology of nonalcoholic fatty liver disease. Am J Clin Pathol. 2007;128:837-47.

10. Evelson P, Susemihl C, Villarreal I, Llesuy S, Rodríguez R, Peredo
H, Lemberg A, Perazzo J, Filinger E. Hepatic morphological changes and oxidative stress in chronic streptozotocin-diabetic rats. Ann Hepatol. 2005;4:115-20.

11. Portincasa P, Grattagliano I, Palmieri VO, Palasciano G. Nonalcoholic steatohepatitis: recent advances from experimental models to clinical management. Clin Biochem. 2005;38:203-17.

12. Clark JM. The epidemiology of nonalcoholic fatty liver disease in adults. J Clin Gastroenterol. 2006;40(Suppl 1):S5-10.

13. Alvarez-Martínez HE, Montaño-Estrada LF, Hernández-Cruz P, Pérez-Campos E. Pathogenic molecular mechanisms in nonalcoholic steatohepatitis. Rev Gastroenterol Mex. 2004;69:176-83.

14. Fraenkel E, Lazúrová I, Fehér J. Role of lipid peroxidation in nonalcoholic steatohepatitis. Orv Hetil. 2004;145:611-8.

15. Andican G, Burçak G. Oxidative damage to nuclear DNA in streptozotocin-diabetic rat liver. Clin Exp Pharmacol Physiol. 2005;23:663-6.

16. Evans JL. Antioxidants: do they have a role in the treatment of insulin resistance? Indian J Med Res. 2007;125:355-72.

17. Calamita LG, Portincasa P. Present and future therapeutic strategies in non-alcoholic fatty liver disease. Expert Opin Ther Targets. 2007;11:1231-49.

18. Duvnjak M, Lerotić I, Barsić N, Tomasić V, Virović Jukić L, Velagić V. Pathogenesis and management issues for non-alcoholic fatty liver disease. World J Gastroenterol. 2007;13:4539-50.

19. Méndez-Sanchez N, Chávez-Tapia NC, Urib, M. An update on nonalcoholic fatty liver disease. Rev Invest Clin. 2004;56:72-82.

20. Rees MD, Kennett EC, Whitelock JM, Davies MJ. Oxidative damage to extracellular matrix and its role in human pathologies. Free Radic Med. 2008;44:1973-2001.

21. Blokhina O, Virolainen E, Fagerstedt KV. Antioxidants, oxidative damage and oxygen deprivation stress: a review. Ann Bot. 2003;91:179-94.

22. Niedowicz DM, Daleke DL. The role of oxidative stress in diabetic complications. Cell Biochem Biophys. 2005;43:289-330.

23. Tan Al, Forbes JM, Cooper ME. AGE, RAGE, and ROS in diabetic nephropathy. Semin Nephrol. 2007;27:130-43.

24. Thomas MC, Forbes JM, Cooper ME. Advanced glycation end products and diabetic nephropathy. Am J Ther. 2005;12:562-72.

25. Ohshiro Y, Takasu N. Molecular mechanisms of diabetic nephropathy. Nippon Rinsho. 2006;64:997-1003.

26. Haque M, Sanyal AJ. The metabolic abnormalities associated with non-alcoholic fatty liver disease. Best Pract Res Clin Gastroenterol. 2002;16:709-31.

27. Yang SQ, Lin HZ, Mandal AK, Huang J, Diehl AM. Disrupted signaling and inhibited regeneration in obese mice with fatty livers: implications for nonalcoholic fatty liver disease pathophysiology. Hepatology. 2001;34:694-706.

28. Wigg AJ, Roberts-Thomson IC, Dymock RB, McCarthy PJ, Grose $\mathrm{RH}$, Cummins AG. The role of small intestinal bacterial overgrowth, intestinal permeability, endotoxaemia, and tumour necrosis factor alpha in the pathogenesis of non-alcoholic steatohepatitis. Gut. 2001;48:206-11.

29. Feldstein AE, Werneburg NW, Canbay A, Guicciardi ME, Bronk SF, Rydzewski R, Burgart LJ, Gores GJ. Free fatty acids promote hepatic lipotoxicity by stimulating TNF-alpha expression via a lysosomal pathways. Hepatology. 2004;40:185-94.

30. Valenti L, Fracanzani AL, Dongiovanni P, Santorelli G, Branchi A, Taioli E, Fiorelli G, Fargion S. Tumor necrosis factor alpha promotes polymorphisms and insulin resistance in nonalcoholic fatty liver disease. Gastroenterology. 2002;122:274-80.

31. Sanyal AJ, Campbell-Sargent C, Mirshahi F, Rizzo WB, Contos MJ, Sterling RK, Luketic VA, Shiffman ML, Clore JN. Nonalcoholic 
steatohepatitis: association of insulin resistance and mitochondrial abnormalities. Gastroenterology. 2001;120:1183-92.

32. Chitturi S, Farrell GC. Etiopathogenesis of nonalcoholic steatohepatitis. Semin Liver Dis. 2001;21:27-41.

33. Robertson G, Leclercq I, Farrell GC. Nonalcoholic steatosis and steatohepatitis. cytochrome P-450 enzymes and oxid. Am J Physiol Gastrointest Liver Physiol. 2001;281:G1135-9.

34. Jensen MD, Haymond MW, Rizza RA, Cryer PE, Miles JM. Influence of body fat distribution on free fatty acid metabolism in obesity. J Clin Invest. 1989;83:1168-73.

35. Friedman JM, Halaas JL. Leptin and the regulation of body weight in mammals. Nature. 1998;395:763-70.

36. Dowman JK, Tomlinson JW, Newsome PN. Pathogenesis of nonalcoholic fatty liver disease. Int J Med. 2010;103:71-83.

37. Roskams T, Yang SQ, Koteish A, Durnez A, DeVos R, Huang X, Achten R, Verslype C, Diehl AM. Oxidative stress and oval cell accumulation in mice and humans with alcoholic and nonalcoholic fatty liver disease. Am J Pathol. 2003;163:1301-11.

\section{Acknowledgement}

To thank Patricia Pintor Reis for reviewing the text translated

\section{Correspondence:}

César Tadeu Spadella

Faculdade de Medicina de Botucatu, Departamento de Cirurgia e Ortopedia

Campus da UNESP

Distrito de Rubião Jr., s/no - Anexo Verde

18618-970 Botucatu - SP Brasil

Tel.: (55 14)3880-1447

spadella@fmb.unesp.br

Received: March 25, 2013

Review: May 27, 2013

Accepted: June 24, 2013

Conflict of interest: none

Financial sources: National Council of Technological and Scientific Development $(\mathrm{CNPq})$ and Coordination of Improvement for Higher Academic Staff (CAPES)

${ }^{1}$ Research performed at Experimental Surgery Laboratory, Faculty of Medicine, Sao Paulo State University (UNESP), Botucatu-SP, Brazil. Part of Master degree thesis, Postgraduate Program in General Basis of Surgery. Tutor: César Tadeu Spadella. 